\title{
CLARIFICATION
}

Anna Leung • Zong Wei Cai · Ming Hung Wong

\section{Environmental contamination from electronic waste recycling at Guiyu, southeast China}

\section{J Mater Cycles Waste Manag (2006) 8:21-33}

The data on PCDD/F emissions appearing in the Abstract and in the Results and discussion section titled "Polychlorinated dibenzo- $p$-dioxins and dibenzofurans as a result of open burning" on pages 21 and 29, respectively, of Vol. 8 (2006), No.1, were published as a result of miscommunication and with insufficient attribution. The original source and correct concentrations can be found in an article by Brian K. Gullet, William P. Linak, Abderrahmane Touati, Shirley J. Wasson, Staci Gatica, and Charles K. King, to be published in the Journal of Material Cycles and Waste Management, Vol. 9 (2007), No. 1.

A. Leung. M.H. Wong ( $\square)$

Croucher Institute for Environmental Sciences and Department of Biology, Hong Kong Baptist University, G/F, Block 5, Low-Rise

Buildings, 32 Ronfrew Road, Kowloon Tong, Hong Kong SAR, China Tel. +852-3411-7746; Fax +852-3411-7743

e-mail: nhwong@hkbu.edu.hk

Z.W. Cai

Dioxin Laboratory, Hong Kong Baptist University, Hong Kong SAR, China 